\title{
MODIFICAÇÃO DA ATMOSFERA NA QUALIDADE PÓS-COLHEITA DE AMEIXAS CV. REUBENNEL ${ }^{1}$
}

\author{
MARCELO BARBOSA MALGARIM², RUFINO FERNANDO FLORES CANTILLANO, \\ ROSA DE OLIVEIRA TREPTOW ${ }^{4}$, EDSON LUIS DE SOUZA ${ }^{5}$, ENILTON FICK COUTINHO
}

\begin{abstract}
RESUMO - Ameixas, de modo geral, têm curto período de conservação pós-colheita, havendo necessidade de otimizar as condições de colheita e de armazenamento. Este trabalho objetivou avaliar o efeito de diferentes modificadores de atmosfera, durante o armazenamento refrigerado, na qualidade pós-colheita de ameixas cv. Reubennel. Frutas no estádio de maturação meio-maduro foram submetidas aos seguintes modificadores de atmosfera: filmes de polietileno de 12,5 e 15 $\mu \mathrm{m}$ de espessura e cera à base de carnaúba e avaliadas após 10; 20; 30 e 40 dias de armazenamento a $0^{\circ} \mathrm{C}$ e UR de 90 $95 \%$. Avaliaram-se a perda de massa, cor, firmeza da polpa, pH, sólidos solúveis (SS), acidez titulável (AT), relação SS/AT, incidência de podridões, escurecimento interno e características sensoriais. Essas avaliações foram realizadas 3 dias após a retirada das frutas da câmara fria. Verificou-se que a cera à base de carnaúba GARFRESH N (BL9,5), sem diluição, e filmes de polietileno de 12,5 e $15 \mu$ m reduziram a perda de massa, porém são impróprios para a modificação da atmosfera, em ameixas cv. Reubennel durante o armazenamento refrigerado. Ameixas cv. Reubennel mantêm a qualidade quando armazenadas durante 30 dias a $0^{\circ} \mathrm{C}$ sem atmosfera modificada.
\end{abstract}

Termos de Indexação: Ameixa; atmosfera modificada; qualidade; frigoconservação; análise sensorial.

\section{MODIFIED ATMOSPHERE ON POSTHARVEST QUALITY OF PLUMS CV. REUBENNEL}

ABSTRACT - Plums quickly loose postharvest quality, which makes imperative to optimize harvest and storage conditions. The objective of this work was to determine the effects of various atmosphere modifiers on the postharvest quality of cold storage plums, cv. Reubennel. Semi-mature fruits were stored under the following atmosphere modifiers conditions: polyethylene films 12,5 or $15 \mu \mathrm{m}$ of thickness; or carnauba wax. After submitted to these conditions the fruits were stored for 10, 20,30 and 40 days in a cold room at $0^{\circ} \mathrm{C}$ and $90-95 \% \mathrm{RH}$. Three days after taken out from the cold storage, the fruits were evaluated about: weight loss; color; firmness; $\mathrm{pH}$; soluble solids (SS); titratable acidity (TA); SS/TA ratio; incidence of rotten and/or internal browning and sensorial characteristics. The use of carnauba wax GARFRESH N (BL9,5) and polyethylene films 12,5 and $15 \mu \mathrm{m}$ reduced weight loss of cold storage plums cultivar Reubennel, but did not appropriately modify fruit atmosphere. Plums cv. Reubennel during cold storage for 30 days at $0^{\circ} \mathrm{C}$ preserved the quality.

Index Terms: Plum, modified atmosphere, quality, cold storage, sensorial analysis.

\section{INTRODUÇÃO}

A cultura da ameixeira tem despertado grande interesse e encontra-se em expansão no Brasil. Porém, problemas fitossanitários, como a escaldadura das folhas (Xillela fastidiosa) e a falta de definição de cultivares e polinizadoras ainda dificultam o desenvolvimento dessa cultura. Apesar disso, o consumidor tem se tornado cada vez mais exigente quanto à qualidade do produto final. Inicialmente, buscavamse frutas com bom tamanho, uniformidade e aparência, mas atualmente são também valorizados outros atributos de qualidade, como sabor, aroma, boa conservação, entre outros.

Em muitos estudos, os tratamentos aplicados visam à melhoria da qualidade. Embora essa expressão seja ampla, podem-se destacar alguns atributos facilmente perceptíveis: aparência, potencial de armazenamento, segurança alimentar, características físicas, químicas, fisiológicas e sensoriais.

Em virtude do aumento da produção e da necessidade de abastecimento permanente de frutas no mercado, o interesse pela póscolheita, nos últimos anos, tem aumentado no Brasil. Isso tem motivado a preocupação no que se refere à preservação da qualidade da fruta, visando ao prolongamento do período de comercialização e maior resistência ao ataque de doenças e à ocorrência de distúrbios fisiológicos.

A refrigeração convencional é o método mais utilizado para o armazenamento de frutas. As ameixas têm, normalmente, um limitado período pós-colheita, devido a fatores como elevada desidratação e perda de textura da polpa, sensibilidade a danos mecânicos durante a colheita e manuseio e incidência de distúrbios fisiológicos e de fungos durante o armazenamento.

O uso de atmosferas modificadas pode proporcionar a manutenção da qualidade de ameixas, reduzindo a perda de massa, a taxa respiratória e a produção de etileno. Entretanto, há necessidade de estudos sobre meios de modificar a atmosfera de frutas para otimizar as condições de armazenamento refrigerado.

O presente trabalho foi conduzido para avaliar a eficiência de diferentes modificações de atmosfera, durante distintos períodos de armazenamento refrigerado, na preservação da qualidade pós-colheita de ameixas (Prunus salicina, Lindl), cv. Reubennel.

\section{MATERIAL E MÉTODOS}

O experimento foi conduzido nos laboratórios de Pós-colheita e Tecnologia de Alimentos do Centro de Pesquisa Agropecuária de Clima Temperado, EMBRAPA/CPACT, localizado na BR 392, km 78, em Pelotas-RS, utilizando-se de ameixas da safra 2001-2002. Foram utilizadas ameixas (Prunus salicina, Lindl.) da cv. Reubennel, provenientes do pomar localizado na Embrapa Clima Temperado, Pelotas-RS.

As frutas foram colhidas manual e aleatoriamente em diversas posições e orientações na planta. A colheita foi efetuada em 26 de dezembro de 2001. Foram descartadas as frutas com injúrias mecânicas, ataque fúngico e/ou de insetos e outros defeitos.

Para a conservação das ameixas, foram testadas atmosferas modificadas com utilização de filmes de polietileno de alta e média densidades com paredes de espessura de $12,5 \mu \mathrm{m}$ e $15 \mu \mathrm{m}$, respectivamente, e cera à base de carnaúba GARFRESH N $(B L 9,5)$. Na seleção das frutas com relação ao estádio de maturação, adotou-se o critério de evolução da cor característica da epiderme (vermelha). As frutas foram colhidas com estádio de maturação meio-maduro, contendo 25 a $50 \%$ de cor característica da cultivar. As frutas foram selecionadas e embaladas em caixas de $5 \mathrm{~kg}$.

\footnotetext{
${ }^{1}$ (Trabalho 111/2004). Recebido: 21/09/2004. Aceito para publicação: 08/12/2005.

${ }^{2}$ Eng. Agr., MSc., Doutorando em Fruticultura de Clima Temperado, UFPel, malgarim@ufpel.tche.br - Fone: 0532758189

${ }^{3}$ Eng. Agr., Dr., Pesquisador, EMBRAPA-CPACT, fcantill@cpact.embrapa.br - Fone: 0532758185

${ }^{4}$ Economista Doméstica, MSc., UFPel, Cx. P. 394, CEP 96001-970, Pelotas-RS.

${ }^{5}$ Eng. Agr., MSc., Ciência e Tecnologia Agroindustrial, UFPel, Pelotas-RS.
} 
Foram aplicados os seguintes tratamentos: T1- Testemunha (sem filme de polietileno e sem cera); T2- Com filme de polietileno de alta densidade (12,5 $\mu \mathrm{m}$ de espessura); T3- Com filme de polietileno de média densidade $(15 \mu \mathrm{m}$ de espessura); T4- Com cera à base de carnaúba GARFRESH N (BL9,5), sem diluição.

Nos tratamentos $\mathrm{T} 2$ e T3, as frutas foram resfriadas por um período de 24 horas antes de serem embaladas nos filmes plásticos. Após acondicionamento das frutas no interior das embalagens, foi usada uma seladora elétrica para fundir as bordas das mesmas. No tratamento T4, a cera foi aplicada segundo a recomendação do fabricante, sendo as frutas imersas na solução de cera.

As frutas foram armazenadas à temperatura de $0 \pm 0,5^{\circ} \mathrm{C}$ durante os períodos de 10;20;30 e 40 dias, correspondendo, respectivamente, a P1, P2, P3 e P4, com umidade relativa entre 90 e 95\%, monitorada, juntamente com a temperatura, por termoigrógrafo (THG1). Após cada período de armazenamento, as frutas foram mantidas por três dias, em ambiente com temperatura controlada de $20 \pm 1^{\circ} \mathrm{C}$, simulando o período de comercialização

$\mathrm{Na}$ colheita e em cada período de armazenamento, após simulação da comercialização, foram avaliadas as seguintes variáveis a) perda de massa calculada a partir das diferenças de massa das unidades experimentais observadas entre o momento da instalação e das avaliações de controle de qualidade, sendo os resultados expressos em porcentagem (\%); b) cor de superfície e de fundo, com duas leituras em lados opostos na região equatorial das ameixas. As leituras foram realizadas com colorímetro Minolta CR-300, com fonte de luz D 65, com $8 \mathrm{~mm}$ de abertura. No padrão C.I.E. L*a*b*, a coordenada $\mathrm{L}^{*}$ expressa $\mathrm{o}$ grau de luminosidade da cor. A coordenada a* expressa o grau de variação entre o vermelho e o verde; e a coordenada $b^{*}$ expressa o grau de variação entre o azul e o amarelo. Os valores $a^{*}, b^{*}$ são usados para calcular o ângulo Hue ou matiz $\left({ }^{\circ} \mathrm{h}^{*}=\operatorname{tang}^{-1} \mathrm{~b}^{*} \cdot \mathrm{a}^{*-1}\right)$; c) firmeza de polpa (FP), medida com penetrômetro manual McCornick FT 327, com ponteira de 5/16 polegadas de diâmetro, após a remoção localizada da epiderme. Foram realizadas duas leituras em lados opostos da secção equatorial das ameixas, expressas em Newton $(\mathrm{N})$; d) $\mathrm{pH}$, determinado com peagâmetro micronal modelo B-271, utilizando-se de uma amostra de suco puro de cada repetição; e) sólidos solúveis (SS), por refratometria, sendo realizada com refratômetro de mesa Shimadzu, com correção de temperatura para $20^{\circ} \mathrm{C}$, utilizando-se de uma gota de suco puro de cada repetição e expressando-se o resultado em ${ }^{\circ}$ Brix; f) acidez titulável (AT), por titulometria de neutralização, com a diluição de $10 \mathrm{~mL}$ de suco puro em $90 \mathrm{~mL}$ de água destilada e titulação com solução de $\mathrm{NaOH} 0,1 \mathrm{~N}$ até que o suco atingisse $\mathrm{pH} 8,1$, expressando-se o resultado em \% de ácido málico, segundo a metodologia de Manzino et al. (1987); g) relação SS/ AT, pelo quociente entre os dois constituintes; h) incidência de podridões, sendo consideradas podres as frutas com características típicas de ataque de patógenos, expressando-se em \% de frutas podres; i) escurecimento interno, determinado através de observação visual, considerando afetadas aquelas com a polpa escurecida, sendo expresso em \% de frutas com sintoma característico; j) enzima polifenoloxidase (PFO), analisada segundo a metodologia descrita por Siriphanich \& Kader (1985) e Flurkey \& Jen (1978). A atividade da PFO foi determinada pelo incremento na leitura espectofotométrica do preparado a $420 \mathrm{~nm}$, realizada dois minutos após a adição do extrato enzimático. Uma unidade de atividade de PFO foi definida como o aumento de 0,01 unidade de absorbância a 420nm por minuto. A atividade foi expressa em unidades de PFO. $\mathrm{min}^{-1} \cdot \mathrm{g}^{-1}$ de massa fresca; $\mathrm{k}$ ) avaliação sensorial, realizada por equipe treinada de 10 julgadores. $\mathrm{O}$ treinamento dos julgadores foi conduzido durante oito semanas. O método empregado foi o Descritivo, teste de avaliação de atributos, segundo Lawless \& Haymann (1998). Os dados foram coletados através de fichas individuais, utilizando escalas não estruturadas de $9 \mathrm{~cm}$, cujo extremo esquerdo corresponde à menor intensidade, e o direito à maior intensidade dos atributos analisados. Os julgadores avaliaram as características de aparência (cor da epiderme, defeitos e desidratação); sabor (doçura, acidez, sabor característico e sabor estranho) e textura (firmeza e suculência). Também foram avaliadas a simulação da comercialização e a qualidade geral, sendo a primeira representada pela intenção de compra, levando-se em consideração as características de aparência, e a segunda, o conjunto de características de sabor e textura. As avaliações de sabor e textura foram realizadas em cabines individuais. As amostras foram cortadas em pedaços, com tamanho-padrão e colocadas em pratos codificados com três dígitos aleatórios. As características de aparência foram realizadas em uma mesa central, no laboratório de avaliação sensorial, com controle de iluminação, sendo as frutas colocadas em bandejas plásticas codificadas.

Para as análises físicas e químicas, o delineamento experimental utilizado foi o de blocos ao acaso, em fatorial de 4 (períodos de armazenamento) x 4 (tratamentos). A unidade experimental foi composta de dez ameixas, sendo cada tratamento repetido três vezes. Os dados foram submetidos à análise de variância, sendo as médias comparadas pelo teste de DMS $(\mathrm{p} \leq 0,05)$.

Para a análise sensorial, o delineamento experimental foi o de blocos casualizados. Após a análise da variância, as médias foram comparadas pelo teste de Tukey $(\mathrm{p} \leq 0,05)$.

\section{RESULTADOS E DISCUSSÃO}

As frutas pertencentes ao controle e as tratadas com cera tiveram aumentos na perda de massa no decorrer do período de armazenamento. As ameixas-controle tiveram os maiores valores em todas as épocas, resultados estes considerados normais, pois as frutas não tiveram proteção contra a perda de água, como as frutas protegidas com filmes de polietileno ou com cera. As ameixas acondicionadas em filme de polietileno tiveram as menores perdas de massa a partir de 30 dias de armazenamento, sendo estatisticamente iguais entre si, enquanto as frutas tratadas com cera tiveram valores superiores aos das frutas protegidas com filmes de polietileno, porém inferiores ao controle, o que indica que houve proteção da cera contra a perda de água das frutas (Figura 1).

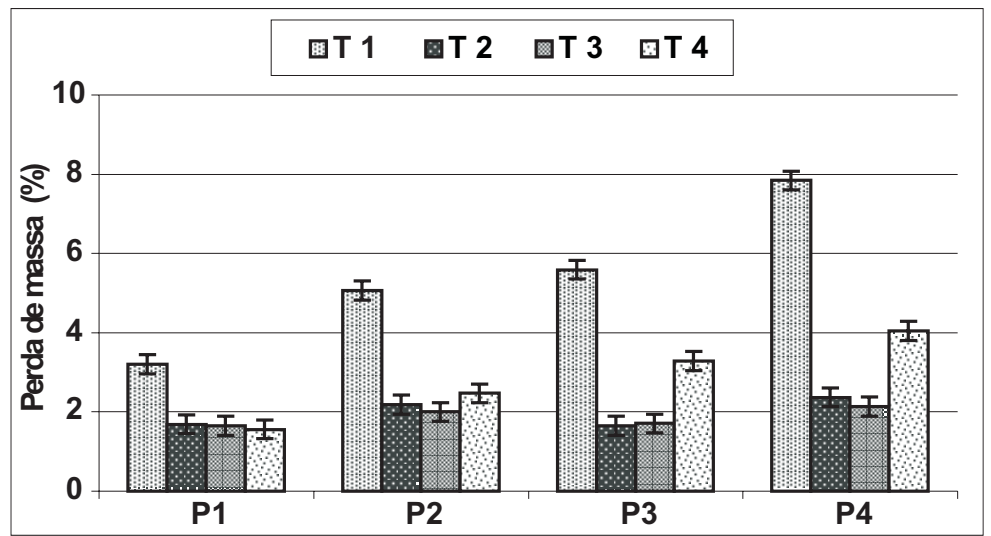

FIGURA 1 - Perda de massa (\%) nos diferentes tratamentos e períodos de armazenamento em ameixas cv. Reubennel. T1testemunha; T2-com filme de polietileno de alta densidade (12,5 $\mu \mathrm{m}$ de espessura); T3- com filme de média densidade ( $15 \mu \mathrm{m}$ de espessura); T4- com cera à base de carnaúba. P1- 10 dias a $0^{\circ} \mathrm{C}+3$ dias a $20^{\circ} \mathrm{C} ; \mathrm{P} 2-20$ dias a $0^{\circ} \mathrm{C}+3$ dias a $20^{\circ} \mathrm{C}$; P3- 30 dias a $0^{\circ} \mathrm{C}+3$ dias a $20^{\circ} \mathrm{C} ; \mathrm{P} 4-40$ dias a $0^{\circ} \mathrm{C}$ +3 dias a $20^{\circ} \mathrm{C}$. Barra vertical: intervalo DMS $(\mathrm{p}<0,05)$.

Os filmes podem causar alterações na taxa respiratória, na acidez titulável, nos sólidos solúveis, no $\mathrm{pH}$, na textura e na perda de massa (Türk \& Özkurt, 1994), os quais podem manter a qualidade da fruta, ou prejudicá-la no caso de filmes impróprios. O uso de filmes plásticos de baixa densidade, como PVC e polietileno, diminuiu as perdas de massa de ameixas durante o armazenamento refrigerado (Filgueiras, 1986; Kluge \& Jorge, 1992).

Com relação à cor, expressa pelo ângulo Hue $\left({ }^{\circ} h\right)$, com exceção das frutas envolvidas com filme de polietileno de alta densidade, os 
TABELA 1 - Coloração da epiderme, firmeza de polpa, pH, escurecimento interno, acidez titulável e relação SS/AT em ameixas cv. Reubennel, nos diferentes tratamentos e períodos de armazenamento.

\begin{tabular}{|c|c|c|c|c|c|}
\hline \multirow{2}{*}{ Variáveis } & \multirow{2}{*}{ Tratamentos } & \multicolumn{4}{|c|}{ Períodos de Armazenamento } \\
\hline & & $\mathrm{P} 1$ & $\mathrm{P} 2$ & $\mathrm{P} 3$ & $\mathrm{P} 4$ \\
\hline \multirow{2}{*}{ Cor (Ângulo Hue) } & $\mathrm{T} 2$ & $21,81 \mathrm{bA}$ & $24,66 \mathrm{cA}$ & $20,86 \mathrm{bA}$ & $19,81 \mathrm{aA}$ \\
\hline & $\mathrm{T} 4$ & $36,00 \mathrm{aA}$ & $29,92 \mathrm{bB}$ & $25,09 \mathrm{aC}$ & $22,09 \mathrm{aC}$ \\
\hline \multirow{3}{*}{ Firmeza de Polpa (N) } & T1 & $14,03 \mathrm{bC}$ & $24,33 \mathrm{aA}$ & $18,47 \mathrm{bB}$ & $19,35 \mathrm{bB}$ \\
\hline & $\mathrm{T} 2$ & $14,47 \mathrm{bB}$ & $17,40 \mathrm{bB}$ & $22,77 \mathrm{aA}$ & $16,25 \mathrm{bcB}$ \\
\hline & $\mathrm{T} 3$ & $19,31 \mathrm{aB}$ & $26,90 \mathrm{aA}$ & $21,00 \mathrm{abB}$ & $24,77 \mathrm{aAB}$ \\
\hline \multirow{4}{*}{$\mathrm{pH}$} & T1 & $2,66 \mathrm{aB}$ & $2,75 \mathrm{aA}$ & $2,74 \mathrm{aA}$ & $2,79 \mathrm{bcA}$ \\
\hline & $\mathrm{T} 2$ & $2,69 \mathrm{aB}$ & $2,80 \mathrm{aA}$ & $2,72 \mathrm{aB}$ & $2,83 \mathrm{bA}$ \\
\hline & $\mathrm{T} 3$ & $2,66 \mathrm{aB}$ & $2,68 \mathrm{bB}$ & $2,70 \mathrm{aAB}$ & $2,75 \mathrm{cA}$ \\
\hline & $\mathrm{T} 4$ & $2,67 \mathrm{aC}$ & $2,75 \mathrm{aB}$ & $2,77 \mathrm{aB}$ & $3,05 \mathrm{aA}$ \\
\hline \multirow{2}{*}{$\begin{array}{l}\text { Escurecimento Interno } \\
\qquad(\%)\end{array}$} & T1 & $0,00 \mathrm{aB}$ & $0,00 \mathrm{aB}$ & $0,00 \mathrm{aB}$ & $16,66 \mathrm{dA}$ \\
\hline & $\mathrm{T} 2$ & $0,00 \mathrm{aB}$ & $0,00 \mathrm{aB}$ & $0,00 \mathrm{aB}$ & $100,00 \mathrm{aA}$ \\
\hline \multirow{2}{*}{$\begin{array}{l}\text { Acidez Titulável -AT } \\
\text { (\% de ácido málico) }\end{array}$} & $\mathrm{T} 3$ & $1,34 \mathrm{aA}$ & $1,33 \mathrm{aA}$ & $1,16 \mathrm{aB}$ & $1,02 \mathrm{aC}$ \\
\hline & $\mathrm{T} 4$ & $1,30 \mathrm{aA}$ & $1,26 \mathrm{abA}$ & $0,93 \mathrm{bB}$ & $0,63 \mathrm{cC}$ \\
\hline \multirow{4}{*}{ Relação SS/AT } & T1 & $12,11 \mathrm{aB}$ & $11,51 \mathrm{aB}$ & $14,07 \mathrm{bA}$ & $14,77 \mathrm{cA}$ \\
\hline & $\mathrm{T} 2$ & $11,43 \mathrm{aB}$ & $13,07 \mathrm{aB}$ & $12,86 \mathrm{bB}$ & $16,53 \mathrm{bA}$ \\
\hline & $\mathrm{T} 3$ & $11,68 \mathrm{aC}$ & $11,66 \mathrm{aC}$ & $13,43 \mathrm{bB}$ & $15,15 \mathrm{bA}$ \\
\hline & $\mathrm{T} 4$ & $11,73 \mathrm{aC}$ & $12,50 \mathrm{aC}$ & $16,61 \mathrm{aB}$ & $24,06 \mathrm{aA}$ \\
\hline
\end{tabular}

Médias seguidas da mesma letra maiúscula na linha ou mesma letra minúscula na coluna não diferem entre si, pelo teste de DMS (p<0,05). T1- testemunha; T2- com filme de polietileno de alta densidade (12,5 $\mu \mathrm{m}$ de espessura); T3- com filme de média densidade ( $15 \mu \mathrm{m}$ de espessura); T4- com cera à base de carnaúba. P1- 10 dias a $0^{\circ} \mathrm{C}+3$ dias a $20^{\circ} \mathrm{C}$; P2- 20 dias a $0^{\circ} \mathrm{C}+3$ dias a $20^{\circ} \mathrm{C}$; P3- 30 dias a $0^{\circ} \mathrm{C}+3$ dias a $20^{\circ} \mathrm{C} ; \mathrm{P} 4-40$ dias a $0^{\circ} \mathrm{C}+3$ dias a $20^{\circ} \mathrm{C}$.

valores diminuíram no decorrer dos períodos de armazenamento. Após 10 dias de armazenamento, os menores valores ocorreram nas frutas protegidas com filmes de polietileno. Essa redução no valor do ${ }^{\circ} \mathrm{h}$ representa o avanço da maturação, proporcionado pela atmosfera modificada com uso de filmes plásticos. Depois de 20 dias de armazenamento, as frutas envolvidas com filme de polietileno de alta densidade mantiveram os menores valores, e, após 30 dias de armazenamento, os menores valores ocorreram nas frutas do controle e nas envolvidas com filme de polietileno de alta densidade. Posteriormente, não houve diferença entre os tratamentos, devido ao avanço da maturação em todos os tratamentos, que resultou na uniformização da cor vermelha (Tabela 1). Possivelmente, a modificação da atmosfera pela utilização de filmes de polietileno de alta e média densidades acelerou o processo de degradação da clorofila.

Segundo Girardi et al. (2000), a alteração na coloração das frutas é uma das principais mudanças que ocorrem no amadurecimento. Essa alteração acontece devido à degradação da clorofila (diminuição dos valores do ${ }^{\circ} \mathrm{h}$ ) e síntese de outros pigmentos, como antocianinas e carotenóides. Com o aumento da maturação, a cor de fundo verde muda para amarelo-clara e, paralelamente, ocorre a síntese de antocianinas, pigmentos de cor vermelha, responsáveis pela cor de superfície.

Os valores de firmeza de polpa diminuíram da colheita $(30,76 \mathrm{~N})$ até 10 dias de armazenamento, com posterior oscilação dos valores (Tabela 1). Possivelmente, isso ocorreu devido à perda de água durante o armazenamento. A diminuição da firmeza de polpa é normal, já que há relação direta entre a evolução da maturação e perecibilidade com a perda de firmeza da polpa (Southy et al., 1990).

$\mathrm{Na}$ variável $\mathrm{pH}$, houve aumento dos valores no decorrer do período de armazenamento. As frutas envolvidas com filme de polietileno de média densidade tiveram menores valores, após 20 dias de armazenamento. Nas frutas tratadas com cera, ocorreu o maior valor após 40 dias de armazenamento (Tabela 1).

Os teores de sólidos solúveis não tiveram diferença significativa entre os períodos de armazenamento. Nas ameixas do tratamento-controle, ocorreram os maiores valores $\left(16,1^{\circ} \mathrm{Brix}\right)$, devido à maior desidratação que proporcionou a concentração dos SS. Segundo Cereta (1999), os SS têm pequenas variações durante o armazenamento, e os aumentos que se verificam, podem ser explicados pela perda de água das frutas. O teor de açúcar em frutas climatéricas, normalmente, aumenta após a colheita e durante o armazenamento por curtos períodos, decrescendo após o armazenamento prolongado (Kluge et al., 1997).

A acidez titulável diminuiu com o aumento do período de armazenamento. Depois de 10 dias de armazenamento, não houve diferença entre os tratamentos. Após 20 dias de armazenamento, as frutas envolvidas com filme de polietileno de alta densidade tiveram o menor valor, mas não diferiram das tratadas com cera. Aos 30 e 40 dias de armazenamento, as frutas tratadas com cera tiveram os menores valores (Tabela 1). Durante a maturação e o armazenamento refrigerado de pêssegos, há redução significativa da acidez, pois os ácidos orgânicos são metabolizados como substrato na respiração (Fishman et al., 1993; Mitchel \& Crisosto, 1995).

A relação SS/AT aumentou ao longo dos períodos de armazenamento, e as frutas tratadas com cera apresentaram a maior relação aos 30 e 40 dias de armazenamento (Tabela 1), devido à redução dos valores da AT. Segundo Chitarra (1997), enquanto os SS aumentam no armazenamento, a acidez diminui, proporcionando aumento da relação SS/AT. A relação SS/AT é importante, uma vez que tem relação com o sabor da fruta.

A porcentagem de podridões não diferiu estatisticamente entre os períodos de armazenamento. A ocorrência de podridões foi menor nas frutas envolvidas com filme de polietileno de média densidade $(1,6 \%)$. As doenças pós-colheita manifestam-se, principalmente, pela ação de fungos que afetam a fruta ainda no campo ou depois da colheita, sendo os efeitos visualizados, posteriormente, durante o armazenamento e/ou comercialização. O principal organismo causador de podridões pós-colheita no experimento foi o fungo Monilinia fructicola, causador da doença chamada podridão-parda.

Durante o armazenamento, ocorreu escurecimento interno 
TABELA 2 - Avaliação das características de aparência (escala sensorial de 9cm) em ameixas cv. Reubennel, nos diferentes tratamentos e períodos de armazenamento.

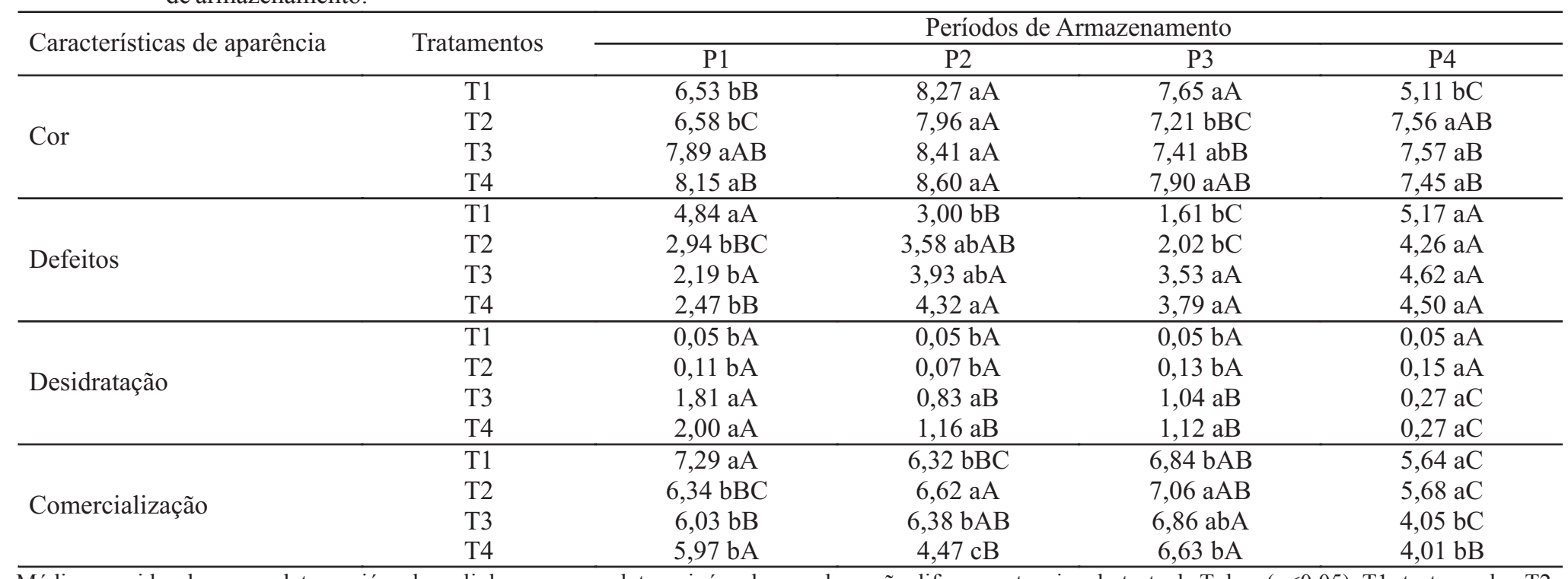

Médias seguidas da mesma letra maiúscula na linha ou mesma letra minúscula na coluna não diferem entre si, pelo teste de Tukey (p<0,05). T1- testemunha; T2com filme de polietileno de alta densidade (12,5 $\mu \mathrm{m}$ de espessura); T3- com filme de média densidade (15 $\mu \mathrm{m}$ de espessura); T4- com cera à base de carnaúba. $\mathrm{P} 1$ 10 dias a $0^{\circ} \mathrm{C}+3$ dias a $20^{\circ} \mathrm{C} ; \mathrm{P} 2-20$ dias a $0^{\circ} \mathrm{C}+3$ dias a $20^{\circ} \mathrm{C} ; \mathrm{P} 3-30$ dias a $0{ }^{\circ} \mathrm{C}+3$ dias a $20^{\circ} \mathrm{C} ; \mathrm{P} 4-40$ dias a $0{ }^{\circ} \mathrm{C}+3$ dias a $20^{\circ} \mathrm{C}$.

apenas aos 40 dias de armazenamento. Nesse período, as frutas do tratamento-controle tiveram menor porcentagem de escurecimento $(16,66 \%)$, enquanto as dos tratamentos T3 e T4 tiveram, respectivamente, 39,25 e $66,66 \%$ de escurecimento, e as do tratamento T2 ficaram totalmente escuras (Tabela 1). O escurecimento interno foi diretamente relacionado com a senescência e as atmosferas modificadas utilizadas no experimento, as quais aceleraram a maturação, o que provocou o aumentou desse distúrbio.

Segundo Crisosto \& Labavitch (2002), o escurecimento interno reduz a aceitação da fruta pelo consumidor, limita o seu potencial de pós-colheita e a vida de mercado.

A atividade da enzima polifenoloxidase (PFO) foi menor nas frutas tratadas com cera (Figura 2). A enzima PFO teve menor atividade a partir de 30 dias de armazenamento (Figura 3). Neste experimento, não se verificou relação entre a atividade da enzima PFO e o escurecimento interno das frutas. Segundo Abreu et al. (1998), as variações na atividade da PFO são decorrentes das espécies, condições de cultivo e manejo das frutas. Por exemplo, em maçãs, há decréscimo da atividade da PFO com aumento da maturação (Coseteng \& Lee, 1987). Brady (1993) encontrou atividade dessa enzima em pêssegos, no momento da colheita e durante a maturação em temperaturas ambientes.

Nas características de aparência, não foi observada diferença entre tratamentos na variável cor, aos 20 dias de armazenamento. As do

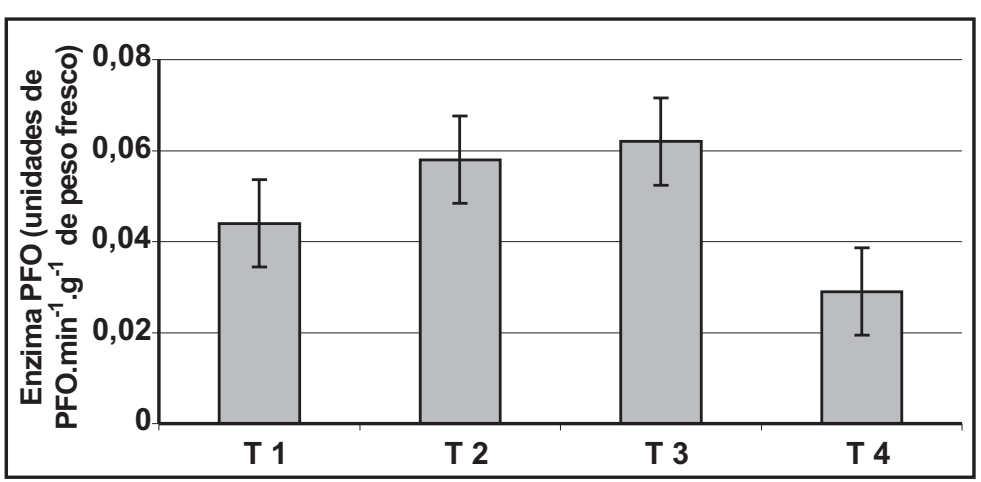

FIGURA 2 - Atividade da enzima polifenoloxidase (unidades de PFO. $\mathrm{min}^{-1} \cdot \mathrm{g}^{-1}$ de peso fresco) nos diferentes tratamentos, em ameixas cv. Reubennel. T1- testemunha; T2- com filme de polietileno de alta densidade $(12,5 \mu \mathrm{m}$ de espessura); T3- com filme de média densidade ( $15 \mu \mathrm{m}$ de espessura); T4- com cera à base de carnaúba. Barra vertical: intervalo $\operatorname{DMS}(\mathrm{p}<0,05)$.

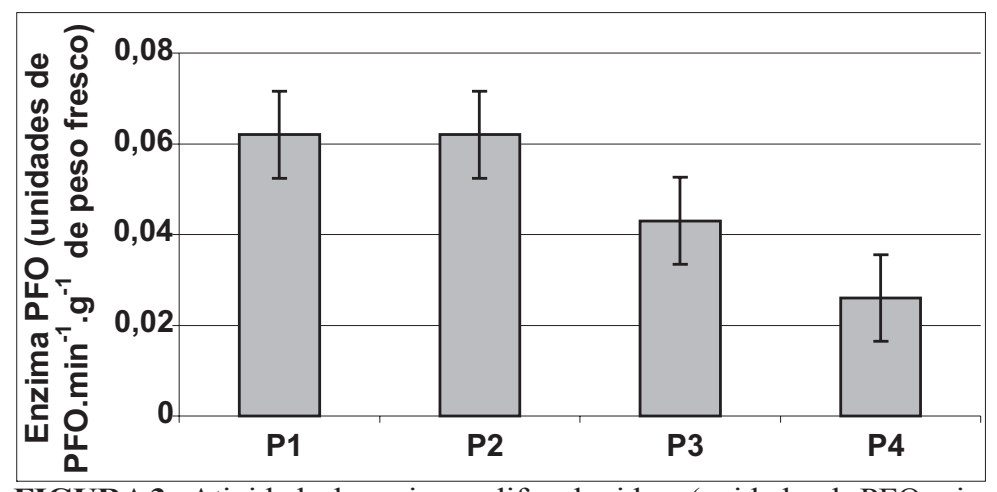

FIGURA3 - Atividade da enzima polifenoloxidase (unidades de PFO.min ${ }^{1} \cdot \mathrm{g}^{-1}$ de peso fresco) nos diferentes períodos de armazenamento, em ameixas cv. Reubennel. P1- 10 dias a $0^{\circ} \mathrm{C}+3$ dias a $20^{\circ} \mathrm{C}$; $\mathrm{P} 2-20$ dias a $0^{\circ} \mathrm{C}+3$ dias a $20^{\circ} \mathrm{C}$; $\mathrm{P} 3-$ 30 dias a $0^{\circ} \mathrm{C}+3$ dias a $20^{\circ} \mathrm{C} ; \mathrm{P} 4-40$ dias a $0^{\circ} \mathrm{C}+3$ dias a $20^{\circ} \mathrm{C}$. Barra vertical: intervalo DMS $(\mathrm{p}<0,05)$.

controle, após 40 dias de armazenamento, apresentaram o menor valor para a referida variável. De maneira geral, as frutas foram classificadas como de intensa coloração avermelhada (Tabela 2).

$\mathrm{Na}$ avaliação dos defeitos, depois de 40 dias de armazenamento, não foi observada diferença entre os tratamentos. As frutas do tratamento T3 demonstraram presença de defeitos similares em todos os períodos de armazenamento. Os tratamentos tiveram de "ligeira a regular" presença de defeitos.

Quanto à desidratação, as frutas dos tratamentos T1 e T2 apresentaram valores similares em todos os períodos de armazenamento. As frutas dos tratamentos T3 e T4 apresentaram valores maiores nos períodos P1, P2 e P3. Mesmo assim, os valores são considerados baixos, classificados como "ligeiro a ausente", comprovando que a umidade relativa do ar na câmara foi adequada durante o armazenamento.

Na simulação da comercialização, as frutas tratadas com cera tiveram os menores valores aos 20 dias de armazenamento. Os menores valores correspondentes ao tratamento $\mathrm{T} 2$ foram registrados no período P4, sem no entanto diferir do observado no período P1.

$\mathrm{Na}$ avaliação das características de sabor, a doçura nos tratamentos T1, T2 e T3 apresentaram os maiores valores nos períodos P2 e P4. Nos períodos P1 e P3, as frutas tratadas com cera apresentaram os maiores valores. No período $\mathrm{P} 2$, não houve diferenças entre tratamentos. De forma oposta, na acidez, as frutas dos tratamentos T3 e T4 apresentaram os menores valores nos períodos P1, P2 e P4. No 
TABELA 3 - Avaliação das características de sabor (escala sensorial de 9cm) em ameixas cv. Reubennel, nos diferentes tratamentos e períodos de armazenamento.

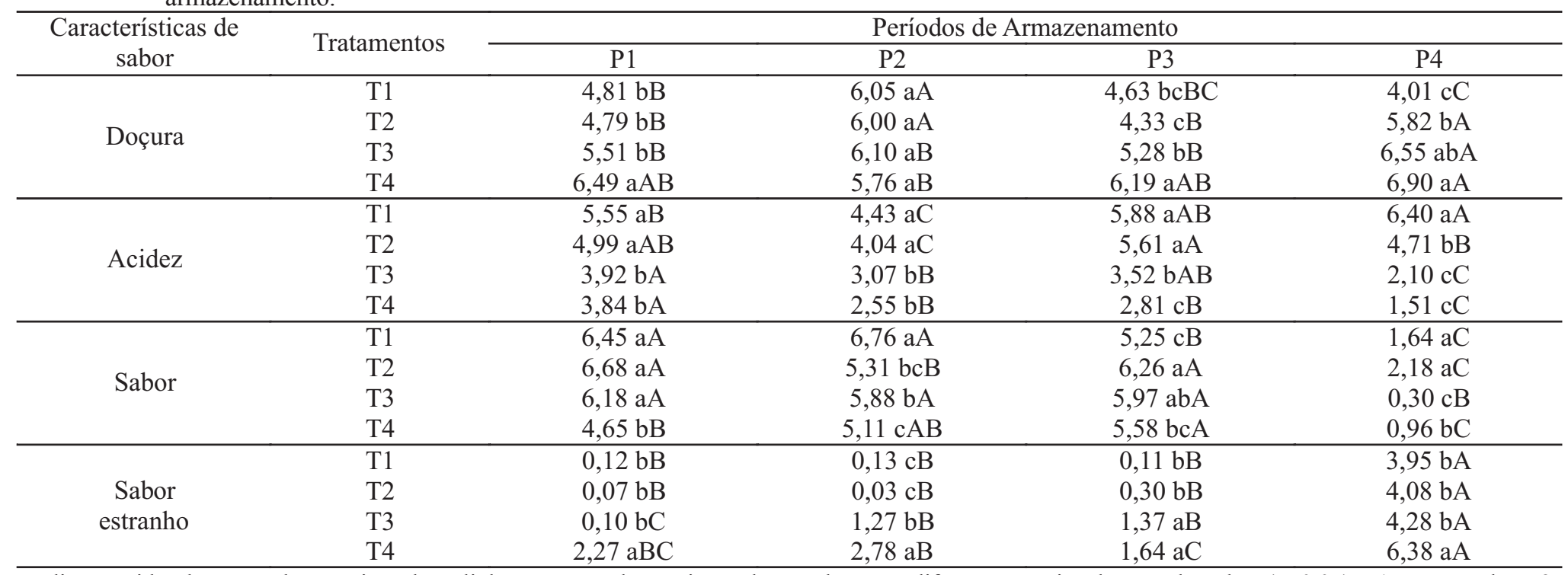

Médias seguidas da mesma letra maiúscula na linha ou mesma letra minúscula na coluna não diferem entre si, pelo teste de Tukey (p<0,05). T1- testemunha; T2com filme de polietileno de alta densidade (12,5 $\mu \mathrm{m}$ de espessura); T3- com filme de média densidade (15 $\mu \mathrm{m}$ de espessura); T4- com cera à base de carnaúba. P110 dias a $0^{\circ} \mathrm{C}+3$ dias a $20^{\circ} \mathrm{C} ; \mathrm{P} 2-20$ dias a $0^{\circ} \mathrm{C}+3$ dias a $20^{\circ} \mathrm{C} ; \mathrm{P} 3-30$ dias a $0{ }^{\circ} \mathrm{C}+3$ dias a $20^{\circ} \mathrm{C} ; \mathrm{P} 4-40$ dias a $0{ }^{\circ} \mathrm{C}+3$ dias a $20^{\circ} \mathrm{C}$.

período P3, as frutas tratadas com cera tiveram menor valor. Esse comportamento oposto entre a doçura e a acidez demonstra maior avanço na maturação das mesmas durante o armazenamento (Tabela 3).

A intensidade do sabor característico, após 40 dias de armazenamento, diminuiu nas frutas de todos os tratamentos. Segundo Crisosto et al. (1997), durante a respiração, são consumidos açúcares, e isso provoca a diminuição na intensidade do sabor.

Nas frutas tratadas com cera, ocorreu maior intensidade de sabor estranho devido ao uso de cera na modificação da atmosfera. $\mathrm{O}$ sabor estranho passou a ser percebido, coincidentemente, com a redução da intensidade do sabor característico, aos 40 dias de armazenamento, indicando sobrematuração das frutas.

De maneira geral, a firmeza foi maior nas frutas do tratamentocontrole em todos os períodos, e menor, nas tratadas com cera nos períodos $\mathrm{P} 2$ e $\mathrm{P} 4$, aumentando ao longo do período de armazenamento nos tratamentos T1 e T2 (Tabela 4). Esse aumento na firmeza foi verificado, também, na análise físico-química, possivelmente devido à perda de massa durante o armazenamento.

A suculência das frutas diminuiu no decorrer do período de armazenamento. Nos diferentes tratamentos, a suculência das frutas foi classificada como de "regular a moderada" (Tabela 4).

A presença de fibras nas frutas teve valores baixos, sendo classificada como não-perceptível (Tabela 4).

$\mathrm{Na}$ avaliação da qualidade geral, aos 10 dias de armazenamento, as frutas dos tratamentos T1, T2 e T3 foram classificadas como de "bom a ótimo", e as tratadas com cera, de "regular a ruim". Aos 20 dias de armazenamento, as frutas do tratamento-controle tiveram os maiores valores, sendo classificadas como de "bom a ótimo", e as frutas dos tratamentos T2 e T3 foram classificadas como de "regular a bom". Já, as frutas tratadas com cera foram classificadas como de "regular a ruim". Aos 30 dias de armazenamento, as frutas de todos os tratamentos foram classificadas como de "regular a bom". Depois de 40 dias de armazenamento, as ameixas dos tratamentos T1, T2 e T3 foram classificados como de "regular a ruim", e as tratadas com cera, de "ruim a péssimo".

Nas frutas tratadas com cera, houve menor qualidade que nos demais tratamentos, independentemente do período de armazenamento, devido, principalmente, à presença de sabor estranho, causado pela

TABELA 4 - Avaliação das características de textura e qualidade geral (escala sensorial de 9cm) em ameixas cv. Reubennel, nos diferentes tratamentos e períodos de armazenamento.

\begin{tabular}{|c|c|c|c|c|c|}
\hline \multirow{2}{*}{ Características de textura } & \multirow{2}{*}{ Tratamentos } & \multicolumn{4}{|c|}{ Períodos de Armazenamento } \\
\hline & & P1 & P2 & P3 & P4 \\
\hline \multirow{2}{*}{ Firmeza } & $\mathrm{T} 2$ & $4,79 \mathrm{bB}$ & $5,16 \mathrm{bAB}$ & $5,19 \mathrm{bA}$ & $5,12 \mathrm{bAB}$ \\
\hline & $\mathrm{T} 4$ & $4,25 \mathrm{bA}$ & $3,30 \mathrm{cB}$ & $4,80 \mathrm{cA}$ & $1,47 \mathrm{dC}$ \\
\hline \multirow{3}{*}{ Suculência } & T1 & $7,00 \mathrm{aA}$ & $5,52 \mathrm{bB}$ & $6,20 \mathrm{aB}$ & $4,99 \mathrm{bC}$ \\
\hline & $\mathrm{T} 2$ & $6,57 \mathrm{abA}$ & $6,06 \mathrm{aAB}$ & $5,73 \mathrm{aB}$ & $5,60 \mathrm{aB}$ \\
\hline & $\mathrm{T} 3$ & $6,15 \mathrm{bA}$ & $5,74 \mathrm{bAB}$ & $5,28 \mathrm{aB}$ & $4,54 \mathrm{bcC}$ \\
\hline \multirow{3}{*}{ Fibra } & $\mathrm{T} 2$ & $0,14 \mathrm{aA}$ & $0,14 \mathrm{aA}$ & $0,28 \mathrm{aA}$ & $0,11 \mathrm{aA}$ \\
\hline & $\mathrm{T} 3$ & $0,24 \mathrm{aA}$ & $0,29 \mathrm{aA}$ & $0,30 \mathrm{aA}$ & $0,25 \mathrm{aA}$ \\
\hline & $\mathrm{T} 4$ & $0,70 \mathrm{aA}$ & $0,70 \mathrm{aA}$ & $0,72 \mathrm{aA}$ & $0,59 \mathrm{aA}$ \\
\hline \multirow{3}{*}{$\begin{array}{l}\text { Qualidade } \\
\text { geral }\end{array}$} & T1 & $7,03 \mathrm{aA}$ & $7,44 \mathrm{aAB}$ & $6,53 \mathrm{aB}$ & $2,75 \mathrm{aC}$ \\
\hline & $\mathrm{T} 2$ & $7,13 \mathrm{aA}$ & $5,83 \mathrm{bB}$ & $6,70 \mathrm{aA}$ & $3,25 \mathrm{aC}$ \\
\hline & $\mathrm{T} 3$ & $7,12 \mathrm{aA}$ & $4,84 \mathrm{cC}$ & $6,23 \mathrm{aB}$ & $3,06 \mathrm{aD}$ \\
\hline
\end{tabular}

Médias seguidas da mesma letra maiúscula na linha ou mesma letra minúscula na coluna não diferem entre si, pelo teste de Tukey (p<0,05). T1- testemunha; T2com filme de polietileno de alta densidade $(12,5 \mu \mathrm{m}$ de espessura); T3- com filme de média densidade $(15 \mu \mathrm{m}$ de espessura); T4- com cera à base de carnaúba. P110 dias a $0^{\circ} \mathrm{C}+3$ dias a $20^{\circ} \mathrm{C} ; \mathrm{P} 2-20 \operatorname{dias}$ a $0^{\circ} \mathrm{C}+3$ dias a $20^{\circ} \mathrm{C} ; \mathrm{P} 3-30$ dias a $0^{\circ} \mathrm{C}+3$ dias a $20^{\circ} \mathrm{C} ; \mathrm{P} 4-40 \operatorname{dias}$ a $0^{\circ} \mathrm{C}+3$ dias a $20^{\circ} \mathrm{C}$. 
utilização de cera para a modificação da atmosfera.

A diminuição da qualidade sensorial ocorreu à medida que aumentou o período de armazenamento. Portanto, é necessário, para cada cultivar e em cada região de produção, determinar o período de armazenamento mais indicado.

\section{CONCLUSÕES}

1. Cera à base de carnaúba GARFRESH N (BL9,5), sem diluição, e filmes de polietileno de 12,5 e $15 \mu \mathrm{m}$ reduzem a perda de massa, porém são impróprios para a modificação da atmosfera, em ameixas cv. Reubennel durante o armazenamento refrigerado.

2. Ameixas cv. Reubennel mantêm a qualidade quando armazenadas durante 30 dias a $0^{\circ} \mathrm{C}$ sem atmosfera modificada.

\section{REFERÊNCIAS}

ABREU, C.M.P.; SANTOS, C.D.; COSTA, L. Efeito da embalagem de polietileno e da refrigeração no escurecimento interno e na atividade de peroxidase e polifenoloxidase, durante a maturação de abacaxi. (Ananas comosus (L) Mess cv. Smooth Cayenne). Ciência e Tecnologia, Campinas. v.22, n.4, p.454-465, 1998.

BRADY, J.C. Biochemistry of fruit ripening. London: Chapman \& Hall, 1993.314p.

CERETA. M. Qualidade do Pêssego (Prunus persica L. Batsch) cv. Eldorado sob armazenamento em atmosfera controlada. 1999. 41f. Dissertação (Mestrado em Fruticultura) - Faculdade de Agronomia Eliseu Maciel, Universidade Federal de Pelotas. Pelotas, 1999.

CHITARRA, A. B. Qualidade, colheita e manuseio pós-colheita de frutas do pessegueiro e da ameixeira. Informe Agropecuário, Belo Horizonte, v.18, n.189, p.68-74, 1997.

COSETENG, M.Y.; LEE, C.Y. Changes in apple polyphenoloxidase and polyphenol concentrations in relation to degree of browning. Journal of Food Science, New York, v.52, n.4, p.985-989, 1987.

CRISOSTO, C.H.; LABAVITCH, J.M. Developing a quantitative method to evaluate peach (Prunus persica) flesh mealiness. Postharvest Biology and Technology, Alexandria, v.25, p.151-158, 2002.

CRISOSTO, C.H.; JOHNSON, R.S.; DEJONG, T. Orchard factors affecting postharvest stone fruit quality. HortScience, California, v.32, n.5, p.820-823, 1997 .
FILGUEIRAS, H.A.C. Conservação pós-colheita de ameixas (Prunus sp cv Roxa de Delfim Moreira) em quatro estádios de maturação. 1986. 131 f. Dissertação (Mestrado em Ciência dos Alimentos) Escola Superior de Lavras, Lavras, 1986.

FISHMAN, M.L.; LEVAJ, B.; GILLESPIE,D. Changes in the physicochemical properties of peach fruit pectin during on tree ripening and storage. Journal American Society of Horticultural Science, Kearneysville, v. 118, n.3, p.343-349, 1993.

FLURKEY, W.; JEN, J. Peroxidase and polyphenol oxidase activies in developing peaches. Journal of Food Science, New York, v.43, p.18261831,1978 .

GIRARDI, C.L.; ROMBALDI, C.V.; PARUSSOLO, A.; DANIELI, R. Manejo pós-colheita de pêssegos cultivar Chiripá. Bento Gonçalves: EMBRAPA, 2000.36 p. (Circular Técnica, 28).

KLUGE, R.A.; JORGE, R.O. Efeito da embalagem de polietileno na frigoconservação de ameixas "Amarelinha". Revista Brasileira de Fruticultura, Cruz das Almas, v.14, n.3, p.21-25, 1992.

KLUGE, R.A.; NACHTIGAL, J.C.; FACHINELLO, J.C.; BILHALVA, A.J. Fisiologia e manejo pós-colheita de frutas de clima temperado. Pelotas: Editora Universitária UFPel, 1997. 163 p.

LAWLESS H.T.; HAYMANN H. Sensory evaluation of food. New York: CHAPMAN \& HALL, 1998. $827 \mathrm{p}$.

MANZINO, M.B.de; SILVESTRI, M.P.de; REARTE, A.E. Identidad y calidad de los alimentos frutihortícolas industrializados. Mendoza: INTI,CITEF, 1987. p.4-5.

MITCHEL, F.G.; CRISOSTO, C.H. The use of cooling and cold storage to stabilize and preserve fresh stone fruits. In: VENBRELL, M., AUDERGON; J.M. Post-harvest quality and derived products in stone-fruits. Lleida: IRTA, 1995. p.125-137.

SIRIPHANICH, J.; KADER, A.A. Effects of $\mathrm{CO}_{2}$ on total phenolics, phenylalanine ammonia lyase and polyphenol oxidase in lettuce. Journal American Society for Horticultural Science, Mount Vernon, v.110, n.2, p.249-253, 1985.

SOUTHY, M.; AUDERGON, J.M.; CHAMBROY, Y. Les critères de qualité. L'Arboriculture Frutière, Paris, n.430, p.18-24, 1990.

TÜRK, R.; ÖZKURT, A.S. The storage of some stone fruits in modified atmosphere. Acta Horticulturae. Wageningen, n.368, p.850-855, 1994. 